\title{
Loneliness of seniors in long-term care institutions and COVID-19 restrictions
}

\author{
Liga Rasnaca $^{1, *}$, Mareks Niklass ${ }^{1}$, Endija Rezgale-Straidoma $^{1}$, and Dace Lina ${ }^{1}$ \\ ${ }^{1}$ University of Latvia, Faculty of Social Science, Riga, Latvia
}

\begin{abstract}
The ageing of society is a significant social and economic challenge in the 21st century Europe. The article analyses loneliness and social isolation among seniors in long-term care (LTC) institutions, as well as how COVID-19 restrictions influence their social isolation. Loneliness and social isolation are different phenomena, but they are interconnected. The feeling of loneliness is a person's psychological state, but it is especially exacerbated among seniors. Loneliness is closely linked to the deficit of social relations. The study employs a mixed methods approach: a survey using the UCLA Loneliness Scale and semi-structured interviews with social workers in LTC institutions during the first wave of COVID-19 in the spring of 2020. A significant number of seniors in LTC experience loneliness or social isolation. The qualitative interviews reveal factors that account for loneliness among seniors. The study also indicates how social workers can reduce seniors' sense of loneliness and social isolation caused by COVID-19 restrictions. Daily routines and pandemic constraints in LTC institutions to some extent limit the social worker's ability to address the loneliness of seniors.
\end{abstract}

Key words - seniors $65+$, loneliness, social isolations, long-term care institutions, the duties of social workers in long-term care.

\section{Introduction}

Europe, including EU member states, is the part of the world where the proportion of seniors continues to rise. In 2020, more than one fifth of the EU-27 population was aged 65 and over. The ageing problem will become more severe in the coming decades. The share of those aged 65 years or above is projected to increase up to $31 \%$ by 2100 (EU-27) [1,2]. The coronavirus (COVID-19) pandemic is a social phenomenon spreading among people and having an impact on individuals, households, and communities [3]. Long-term care (LTC) institutions have been one of the epicentres of COVID-19.

Loneliness and social isolation are phenomena, which affect seniors 65+ more often than other age groups [4]. The feeling of loneliness is a person's psychological state, but it is especially exacerbated among older people. Loneliness closely relates with the deficit of social relations [5]. A person is considered socially isolated if they live alone, have less than a monthly contact with friends or the family, and do not belong to a group (religious congregation, sports club, work or volunteer organization, etc.). Social isolation and loneliness are interconnected and can have adverse effects on seniors' health and wellbeing [6].

\footnotetext{
*Corresponding author: liga.rasnaca@lu.lv
} 
The aim of the study is to analyse the feeling of loneliness and social isolation among seniors in LTC, as well as how COVID-19 restrictions influence their social isolation. The COVID-19 outbreak poses significant challenges for seniors. First, seniors have higher risks for developing serious complications in case of infection. Second, the development of illness in old age has the potential to deteriorate their functioning and health status significantly. Third, stronger confinement measures are directed at seniors significantly changing their dayto-day lives and restricting their independence, especially in LTC where restrictions on daily routines and autonomy are necessary to ensure care standards. These problems will be ever more exacerbated for those in poor health living in LTC.

COVID-19 will have a significant impact on seniors' social connections. Limiting exposure to COVID-19 requires seniors to self-isolate and rely on support networks. The latest edition of 'How's Life?' by OECD highlights the problem of social isolation among seniors. In times of need, seniors are three-times more likely than younger people to report not having a family member or friend that they can rely on (the average number in the population is one in 11 people) [7].

The seniors $65+$ are the most affected but the effects on them do not depend on biological factors alone. Several factors contribute to the total impact. The seniors $65+$ are exceptionally exposed to death from the disease, but also to risks, arising from isolation and weak social ties compounded by the fragmentation of health and social care services. Social workers like many health and behavioural health professionals are concerned about the impact of COVID19 on their wellbeing, the people to whom they provide services, their families, and others in the community. The theoretical background is based on concepts of vulnerability, loneliness, and social isolation of seniors 65+. A methodologically mixed method approach is applied (UCLA loneliness scale and interviews with social workers).

\section{Theoretical background}

The theoretical frame of this study is based on 'social cage' theory, the concepts of vulnerability, loneliness, and social isolation during COVID -19 pandemic in LTC for seniors. The restrictions imposed due to COVID-19 may strengthen the necessity of physical and, consequently, also of social isolation in LTC institutions. 'Social cage' theory, as Nicki Lisa Cole, senior researcher at Technical University Graz, described, is rooted in Max Weber's rational theory of the bureaucratic power system theory as "iron cage". This theory is interpreted by a representative of functionalism Talcott Parson. The main idea in this theory is that "the technological and economic relationships that organized and grew out of capitalist production became fundamental forces in society" [8]. In a narrower, specific sense, social norms, standards of behaviour are a 'social cage', shaping the life of seniors in LTC institutions. This 'social cage' includes seniors' daily activities and constraints during COVID-19. Social workers are in a 'social cage' formed by their administrative duties and interaction with seniors.

Authors have carried out theoretical analysis to find out categories for empirical analysis. Firstly, authors will interpret the application social cage theory for seniors in LTC, and their vulnerability. Secondly, the concepts such as LTC and loneliness and social isolation will be described. Lastly, authors will look at the factors influencing social isolation and loneliness of seniors during COVID-19 pandemic in LTC institutions.

Due to the COVID-19, the restrictions of social contacts involved in LTC facilities increased isolation and vulnerability to abuse and neglect of senior residents. However, "social relationships are integral to human wellbeing, and research consistently documents that social integration and support have protective effects on morbidity and mortality outcomes" [9]. The 'situation of emergency' was declared in Latvia on 12th of March 2020. It was only one 
day after the World Health Organization (WHO) declared COVID-19 pandemic [10]. The main restrictions were an almost complete ban on visits, restrictions on indoor movement, the suspension of cultural activities and general requirements for distancing and hygiene [11]. According to recommendations, the restrictions were applied to those LTC institutions where COVID-19 was not identified. Therefore, restrictions affected all residents and employees in LTC institutions. The stricter rules were explained in guidelines addressed for those institutions where the disease was diagnosed [12]. The main responsibility for implementation of recommendations and guidelines was imposed on the heads of LTC institutions. LTC is a system that provides social, personal and health care services over a long period to people who suffer from some form of functional impairment including limited access to daily activities.

Seniors with disabilities, mental disorders and long-term chronic illnesses are the vast majority in need of LTC services [13,14]. A person's weakness, chronic illness or disability can result in a person being confronted with limitations in various areas and activities in their daily lives. Some authors understand 'social cage' as overall social order, based on industrial development in contemporary society. LTC institutions are a product of social development in society [15]. Economic, social, and cultural resources and traditions influence LTC in any society. As a part of the social service system, LTC could be characterized as a relatively autonomous element with a particular set of values, norms, and role set, forming a specific 'social cage'. The main aspects of care are cultural and spatial boundaries, as well as care ethics [16]. LTC means not only a financial burden on society, but also the ability to provide health and social care services, housing, and an appropriate environment to ensure the highest possible quality of life [17]. LTC should include important quality-of-life domains such as security, comfort, meaningful activity, relationships, enjoyment, dignity, autonomy, privacy, individuality, spiritual wellbeing, and functional competence $[18,19]$.

LTC is the responsibility of the state and local government, non-governmental organizations (NGOs), communities, social workers, social work specialists, health care specialists and relatives. Several stakeholders, state and local governments, NGOs, and private organizations, are involved in providing LTC for seniors. LTC for seniors is an essential part of their wellbeing and provision of decent life in older age. The seniors' cultural needs and intergenerational contacts are an essential part of life quality in LTC institutions [19,20]. LTC institutions in Latvia are divided into state, municipal and private institutions. The seniors' life in a LTC institution is, probably, accepted in society as a social necessity but not the preferred solution for the individual. Seniors should only move into nursing and residential LTC when treatment, rehabilitation and other alternatives have been exhausted. Seniors as residents of LTC institution should consistently receive high-quality care that is person-centred and dignified and have the same access to all necessary health care as other seniors have who are living in other settings [22].

Loneliness is a subjective feeling of an individual who feels isolated. Social isolation has been associated with many public health risks and conditions among the senior population [23]. The chronic loneliness means negative feelings that can arouse from long-term deficit of social needs and connections. Each person has different needs for time to be alone and to have social contacts [24], so chronic loneliness means permanent recurrent unpleasant feelings. Chronic loneliness occurs when a person has a lack of social communication links with someone for an extended period.

Social isolation, separation from ordinary friends and relatives can promote the loneliness of seniors. Rapid changes in the environment, new, unusual conditions can also reinforce a feeling of loneliness, which can be temporary if you manage to adapt to new conditions. If adaptation to the new environment is not so successful, then loneliness can become long lasting, i.e., chronic. It can also affect mental and general health [25]. There is no one general definition but social isolation refers to an objective state of having only few, infrequent social 
contacts with emotionally significant people (friends, family members) $[19,26]$. Social isolation has been put under high risk due to the COVID-19. For example, social distancing has been an essential public health strategy during the coronavirus pandemic. For seniors, especially those, who are staying in LTC institutions, social distancing and stay-at-home measures also limit their mobility and visits with their relatives and friends and it increases their risk to be even more socially isolated [27]. Seniors 65+ are at heightened risk of social isolation because of age-related changes in their social networks (e.g., widowhood, retirement), relocation, and physical changes, which can impede their ability to participate socially. Social isolation is a particular challenge for seniors because it reflects a limited reserve of support to draw on when in need. Health research data show a significant impact of loneliness and social isolation on seniors' health status in the long term $[4,28]$.

\section{Data and methods}

The research design is a mixed method case study. To ensure methodological triangulation, data was obtained from various sources. The first data source was survey in LTC institution "Gailezers" for seniors. The survey was conducted just before WHO declared the COVID-19 pandemic and Latvian government confirmed state of emergency. The second source of data was 10 semi-structured interviews with social workers of state and municipal LTC institutions during second wave of COVID-19 pandemic in Europe from January 6 to March 11, 2021. The qualitative interviews reveal influencing factors that cause loneliness to seniors in a LTC institution.

\section{Results}

\subsection{The survey data}

The survey data are drawn from a study carried out by Dace Lina, a graduate student at the University of Latvia. In her Master thesis "The loneliness problem of seniors in long-term social care institution", she uses the UCLA Loneliness Scale to measure the level of loneliness in three LTC institutions in Riga. The study was conducted from January 6 to March 11, 2021. In this article, the authors use a subset of the data obtained from 100 surveyed individuals in a LTC institution "Gailezers". In comparison with other LTC institutions, the subset contains all answers to the questions included in the original questionnaire.

The UCLA Loneliness Scale was originally developed by Russell et al. (1978) [29]. The current study utilizes a modified version (Version 3) [30]. It has 20 questionnaire items asking respondents to identify their answers on a four-point Likert scale from "never" to "always" (corresponding numerical values from 1 to 4). Respondents are asked not only to identify their feelings of loneliness ("I feel completely alone") but also interconnectedness to others ("There are people who really understand me"). Obtained scale values (a sum of 20 item scores) thus vary from 20 (loneliness not identifiable) to 80 (extreme loneliness). In scientific literature, values from 20 to 34 denote a low degree of loneliness, from 35 to 49 a moderate degree of loneliness, from 50 to 64 a moderately high degree of loneliness, and 65-80 a high degree of loneliness [31]. Table 1 provides a detailed overview of the empirical analysis.

Most respondents in the LTC institution "Gailezers" experienced a moderately high degree of loneliness. The sample mean is 53.99. A typical respondent scored 55 (median) on the UCLA Loneliness Scale. To put that into a perspective, a large scale study $(n=1186)$ carried out in nursing home in Portugal in 2016 reveals that most residents there experienced a low degree of loneliness with the mean value of 32.3 [32]. It should be noted that various 
factors could account for such differences (different cultural contexts, COVID-19), which is not the focus of this study.

In most cases the distributions of values were negatively skewed, they failed the assumptions of normal distribution. The normality of the distributions was assessed with the Kolmogorov-Smirnov test. Therefore, Mann-Whitney U test was conducted to determine whether there is a difference in the UCLA Loneliness Scale scores between males and females, younger and older respondents as well as those with or without children. The data analysis reveals that women experience higher levels of loneliness than men do $(U=87.5$, $p<p<0.05)$. Respondents in the age group 75+ identify higher values on the UCLA Loneliness Scale than younger respondents identify $(U=734, p<0.05)$. Lastly, and somewhat unexpectedly, seniors who have children feel significantly lonelier than those without children $(U=835, p<0.05)$. Unfortunately, the original questionnaire includes very few background variables that might explain these results. To sum up, the survey carried out in LTC institution "Gailezers" in early 2020 indicate that residents there experience a moderately high degree of loneliness. Most likely, the COVID-19 exacerbated the situation because contacts with others (relatives, friends) were considerably limited.

Table 1. UCLA Loneliness Scale scores by gender, age, and groups with or without children.

\begin{tabular}{|c|c|c|c|c|c|c|c|}
\hline & Total & Male & Female & Age 63.5-74 & Age 75+ & Have children & Have no children \\
\hline Valid answers & 100 & 32 & 68 & 27 & 73 & 49 & 51 \\
\hline Mean & 53.99 & 48.97 & 56.35 & 52.56 & 54.52 & 55.14 & 52.88 \\
\hline Median & 55.00 & 48.00 & 57.00 & 51.00 & 55.00 & 56.00 & 54.00 \\
\hline Mode & 59.00 & 48.00 & 59.00 & 48.00 & 55.00 & 59.00 & 54.00 \\
\hline Std. Deviation & 4.41 & 2.99 & 2.64 & 4.39 & 4.33 & 4.34 & 4.24 \\
\hline Skewness & -0.52 & 0.40 & -0.49 & 0.26 & -0.83 & -0.66 & -0.54 \\
\hline Std. Error of Skewness & 0.24 & 0.41 & 0.29 & 0.45 & 0.28 & 0.34 & 0.33 \\
\hline Kurtosis & -0.78 & -0.42 & -0.60 & -1.62 & -0.02 & -0.97 & -0.61 \\
\hline Std. Error of Kurtosis & 0.48 & 0.81 & 0.57 & 0.87 & 0.56 & 0.67 & 0.66 \\
\hline Minimum & 44.00 & 44.00 & 50.00 & 47.00 & 44.00 & 47.00 & 44.00 \\
\hline Maximum & 61.00 & 55.00 & 61.00 & 59.00 & 61.00 & 61.00 & 59.00 \\
\hline
\end{tabular}

\subsection{Interview data}

The results of semi-structured interviews are indicating three major factors that cause an increase of loneliness among seniors during COVID-19: infrastructure of facility, increase in administrative burden for service providers, and social isolation of senior residents.

\subsubsection{Infrastructure of facility}

Due to COVID-19 a lot of imperfections were discovered in the infrastructure of LTC institutions that lead to the conclusion that some buildings are not suitable to facilitate LTC for seniors in case of pandemics, especially those LTC institutions which have been changed from old hospitals, schools and even hotels. The setup of these institutions is inappropriate to prevent the spread of viruses (only one entrance, one staircase, etc.). As a solution to that during the first wave of COVID-19, those seniors who were infected got isolated from the other residents and their meals were served to their rooms only. So seniors were missing their social time with the others what is a crucial part of their daily routine and wellbeing. Due to lack of additional staircases in LTC institutions, residents who are infected were not allowed to leave their floor and, as a result, they felt trapped and even more isolated. The placements 
of the seniors' rooms were changed by reorganizing one floor for those who are sick with COVID-19. It forced still healthy seniors to leave their own room by placing them in another floor and different room.

\subsubsection{Increase of administrative burden for service providers}

Another factor that causes senior loneliness, is an increase in administrative burden for care service providers (carers, social carers, social workers) creating 'social cage' and leaving less time available for care workers to spend with seniors. New control measures taken by the authorities of the welfare system put an additional strain on supervisors and social workers. For example, writing more reports on daily basis and keeping a record on supplies such as masks, disinfectors, protective wear during the pandemics.

The new restrictions and virus precautions are increasing workload for everyone who works in LTC institutions. Carers who are working with infected seniors are wearing special protective outfits that must be changed frequently. Carers must disinfect all surfaces at least three times per day (railings, door handles, bathrooms etc.) and help cleaner to clean rooms. Seniors complain about their rooms being cleaned several times a day because it is disturbing. Seniors are not allowed to leave their room without the mask. For some seniors wearing a mask is difficult to understand and accept, especially for those who have dementia.

\subsubsection{Social isolation for senior residents}

Third factor that causes loneliness during COVID-19 among seniors is social isolation. To prevent the spread of COVID-19 in the institution, the visitors are not allowed in LTC institutions. To compensate for the lack of face-to-face visits with friends and relatives, LTC institutions are trying to organize the alternative ways of communication for seniors by using technologies such as smartphones, iPad, and computers.

For some seniors, it is difficult to accept and understand new digital communication technologies (DCT) to use instead conventional phone. Most of the seniors do not have their own phones in order to contact their relatives and friends. LTC institutions are trying to provide seniors with DCT. There is a time limit for each conversation.

During the COVID-19, seniors are limited in mobility by restrictions to go outside the LTC institution building. For most of them, it is hard to adapt to these new rules and difficult to accept mobility restrictions. Instead of going to shops by themselves whenever they wanted, now the grocery shopping is done by carers for the seniors. Parcels and deliveries are allowed in limited amounts and before seniors can receive them, the parcels get disinfected.

Even though the institutional environment is different from living in your own home, some LTC institutions tried to compensate for the lack of home environment for the seniors by organizing their cultural life. Before COVID-19 seniors used to go on short trips, excursions, picnics in nature, attended plays in the theatres etc., but during the pandemics all these activities were cancelled. Before COVID-19 spread institutions regularly organized several cultural events each month of a wide variety of performing arts such as choir singing, solo singing, folk dancing, orchestral music, talk shows etc. Seniors themselves participated in a variety of cultural events, too.

\section{Discussion}

The UCLA scale shows a higher score of loneliness and social isolation than similar studies [32]. It could be described by differences in social care organization in LTC institutions, 
overload of social workers and all staff in Latvian LTC institutions $[17,18]$. Age and gender differences in the results of social isolation and loneliness are similar to those in previous studies on social isolation [32].

Social care for seniors has not been a priority in social policy before the pandemic and the quality of social care services needs to be improved. Limited time and budget are influencing quality of services [6]. The personal interests of seniors are not always considered. It is difficult for carers in LTC institution to provide emotional support for seniors since this requires interpersonal communication and time for it. The study results suggest that the feeling of loneliness and social isolation is a problem to be solved in LTC institutions. Social workers are one of the parties involved in the search for a solution.

The changes in social contacts, lack of familiar visitors from outside as well as distancing and spatial restrictions were well designed and necessary to reduce the spread of the disease in LTC institution, but they negatively affected the mental wellbeing of seniors [3]. The COVID19 restrictions only strengthened social isolation due to insufficient technological support in LTC and lack of necessary skills of seniors.

Seniors are more likely to rely on social support of relatives and family members $[6,19]$. The restrictions of visitors, relatives, and family members in LTC institutions contributed to seniors' vulnerability. Quantitative and qualitative data suggests that already high loneliness rates before COVID-19 during the pandemic may have contributed to chronic loneliness among seniors, especially seniors $75+[25,22]$.

The long-term effect of COVID-19 restrictions on social and mental wellbeing of seniors will be observable after the pandemic and need to be studied. The social cage in the studied LTC institutions is LTC daily routine as well as premises, spatial structure to some extent limit the social worker's ability to reduce the loneliness of seniors, especially in the conditions of pandemic constraints. LTC for seniors has increased their vulnerable position during the COVID-19. Frequent staff change, carers burnout, and getting sick with virus brings LTC institutions affect quality of care.

Restrictions for some seniors are life threatening. They are suffering from depression and anxiety. Some of the seniors who had some functional disorders now are at higher risk to become bed rested. Seniors feel trapped, lonely, bored, and isolated.

\section{Conclusions}

During the COVID-19 in LTC institutions, both senior residents and staff members are under higher risk to be infected. To protect senior residents and staff worldwide and nationwide, organizations and local authorities have developed administrative guidelines and recommendations on how to protect people and stop the spread of COVID-19.

On one hand, measures have been developed to protect seniors and staff in LTC institutions for a good reason. On the other hand, restrictions and new administrative burden created a 'social cage' for both social workers and seniors.

The results show that within new measures for protection of people, LTC institutions are facing several new challenges that emphasise the vulnerability of both carers and seniors. The survey results show that feeling of loneliness and social isolation is higher in Latvian LTC institutions than in similar LTC institutions of other countries.

There was a great deal of additional responsibility and a great deal of administrative work for the heads of LTC institutions and social workers. The individualization of services necessary for each senior was troubled during the COVID-19. The additional duties of social workers and other staff did not leave enough time for the necessary interpersonal communication with seniors, and it increased social isolation. 
Grouping residents into those who were sick and those who were still healthy prevented the spread of the COVID-19 in LTC institutions, but created bigger isolation and made seniors to adapt to the new circumstances.

Due to restrictions during COVID-19 all cultural events and outdoor activities in LTC institutions were cancelled though they are part of person's wellbeing, and seniors should not be excluded from that for long time.

\section{References}

[1] Eurostat. Ageing Europe. Available at: https://ec.europa.eu/eurostat/cache/digpub/ageing [viewed 12.07.2021] (n.d.)

[2] SAPEA, Scientific Advice for Policy by European Academics. Transforming the future of ageing. Berlin: SAPEA., Available at: https://www.sapea.info/wpcontent/uploads/tfa-report.pdf [viewed 13.07.2021] (2019)

[3] J.V. Bavel, K. Baicker, P.S. Boggio, Using social and behavioural science to support COVID-19 pandemic response. Nat Hum Behav 4, 460-471 https://doi.org/10.1038/s41562-020-0884-z (2020)

[4] M. Berg-Weger, J. Morley, Loneliness and Social Isolation in Older Adults during the Covid-19 Pandemic: Implications for Gerontological Social Work. Nutr Health Aging 14, 1-3, DOI: 10.1007/s12603-020-1366-8 PMCID (2020)

[5] R. Findlay Interventions to reduce social isolation amongst older people: Where is the evidence? Ageing Soc. 23(5), 647-658, DOI: 10.1017/S0144686X03001296 (2003)

[6] A. Dickens, S. Richards, S. Greaves, C.J. Campbell, Interventions targeting social isolation in older people: a systematic review. Medicine. BMC public health (2011)

[7] OECD (The Organisation for Economic Co-operation and Development), Integrating Social Services for Vulnerable Groups: Bridging Sectors for Better Service Delivery, OECD Publishing, Paris. http://dx.doi.org/10.1787/9789264233775-en [viewed 19.05.2021] (2015)

[8] N.L. Cole, Understanding Max Weber's 'Iron Cage'. Available at.: https://www.thoughtco.com/understanding-max-webers-iron-cage-3026373 [viewed 19.05.2021] (2019)

[9] K. Gerst-Emerson, J. Jayawardhana, Loneliness as a public health issue: the impact of loneliness on health care utilization among older adults. Am. J. Public Health, 105(5), 1013-1019. https://doi.org/10.2105/AJPH.2014.302427 (2015)

[10] WHO, Archived: WHO Timeline - COVID-19 Available at: https://www.who.int/news/item/27-04-2020-who-timeline-covid-19 [viewed 19.05.2021] (2020)

[11] Labklājības ministrija (Ministry of Welfare) Ieteikumi ilgstošas sociālās aprūpes un sociālās rehabilitācijas institūcijām ierobežojošo pasākumu piemērošanai. In English: Recommendations for long-term social care and social rehabilitation institutions for the application of restrictive measures. Available at: http://www.lm.gov.lv/lv/aktuali/aktuali-list/91698-covid-19-noradijumi-pakalpojumusniedzejiem-ilgstosas-socialas-aprupes-institucijas [viewed10.05.2021] (2020)

[12] Veselības Ministrija. (Ministry of Health).VM Rekomendācijas sociālās aprūpes iestādēm - algoritmi. In English: Recommendations for social care institutions - algorithms. Available at: https://www.vm.gov.lv/sites/vm/files/media_file/ja-darbiniekamcovid.pdf [viewed 20.05.2021] (2020)

[13] R.L. Barker, The Social Work Dictionary (6th ed.). Washington, DC: NASW Press. (2014) 
[14] O.D. Cardona, M.K. van Aalst, J. Birkmann, M. Fordham, G. McGregor, R. Perez, R.S. Pulwarty, E.L.F. Schipper, \& B.T. Sinh, Determinants of risk: exposure and vulnerability. In book: Managing the Risks of Extreme Events and Disasters to Advance. Climate Change Adaptation [C.B.Field,V. Barros, T.F. Stocker, D. Qin, D.J. Dokken, K.L. Ebi, M.D. Mastrandrea, K.J. Mach, G.K. Plattner, S.K. Allen, M. Tignor \& P.M. Midgley (eds.)]. A Special Report of Working Groups I and II of the Intergovernmental Panel on Climate Change (IPCC). Cambridge University Press, Cambridge, UK, and New York, NY, USA, pp. 65-108 (2012)

[15] A. Maryansky, J. Turner, The social cage: human nature and the evolution of society. Stanford, Stanford Univ. Press (1992)

[16] J. Phillips, Care. Key concepts. Cambridge: Polity Press (2007)

[17] A. Österle, (Ed.) Long-term Care in Central and South-Eastern Europe. Berlin: Peter Lang https://doi.org/10.3726/978-3-653-01021-3 (2011)

[18] R.A. Kane, Long-Term Care, and a Good Quality of Life: Bringing Them Closer Together, Gerontologist 41(3), 293-304. https://doi.org/10.1093/geront/41.3.293 (2001)

[19] M. Berg-Weger, J.E. Morley, Loneliness in older age: An unaddressed health problem. J Nutr Health Aging 24(3), 243-245 (2020)

[20] G.L. Maddox, Deinstitutionalization. (Ed.) Encyclopaedia of Ageing: A Comprehensive Resource in Gerontology and Geriatrics, pp. 274-275. New York, Springer Publishing Company (2013)

[21] L. Rasnača, E. Rezgale-Straidoma, Challenges While Caring for Older People in their Homes Economic Science for Rural Development 2018: 19th International Scientific Conference, 9-11 May, 2018, Latvia: Proceedings: Latvia University of Life Sciences and Technologies 49, 394-401, DOI: 10.22616/ESRD.2018.158 (2018)

[22] L. Rasnača, E. Rezgale-Straidoma, Intergenerational Cultural Programs for Older People in Long-term Care Institutions: Latvian Case. In Ł. Tomczyk \& A. Klimczuk (Eds.), Selected Contemporary Challenges of Ageing Policy Kraków: UniwersytetPedagogiczny w Krakowie. 189-219 (2017)

[23] D. Oliver, C. Foot, R. Humphries, Making our health and care systems fit for an ageing population. London, The King's Fund. Available at: https://www.kingsfund.org.uk/publications [viewed 20.06.2021] (2014)

[24] National Academies of Sciences, Engineering, \& Medicine. Social isolation and loneliness in older adults: Opportunities for the health care system. Washington, DC: The National Academies Press. https://doi.org/10.17226/25663. (2020)

[25] C. Raypole, Is Chronic Loneliness Real? T. Legg, (Ed). CRNP Available at:https://www.healthline.com/health/mental-health/chronic-loneliness [viewed 15.06.2021] (2019)

[26] A. Ypsilanti, L. Lazuras, P. Powell, P. Overton, Self-disgust as a potential mechanism explaining the association between loneliness and depression. J. Affect. Disord. 243, 108-115, Doi: 10.1016/j.jad.2018.09.056 (2019)

[27] A. Chamberlain, W. Duggleby, P. Teaster, C. Estabrooks, C. Characteristics of Socially Isolated Residents in Long-Term Care: A Retrospective Cohort Study,GGM 6(5), DOI:10.1177/2333721420975321. [viewed 14.06.2021] (2020)

[28] E.E. Office, M.S. Rodenstein, T.S. Merchant, T.R. Pendergrast, L.A. Lindquist, Reducing Social Isolation of seniors during COVID-19 through Medical Student Telephone Contact. JAMDA 21(7) 948-950 (2010)

[29] D.W. Russell, L.A. Peplau, M.L. Ferguson, Developing a Measure of Loneliness. J Pers Assess 42, 290-294. http://dx.doi.org/10.1207/s15327752jpa4203_11 (1978) 
[30] D.W. Russell, UCLA Loneliness Scale (Version 3): Reliability, Validity, and Factor Structure, J Pers Assess 66(1), 20-40, DOI: 10.1207/s15327752jpa6601_2 (1996)

[31] A.D. Kusaslan, Evaluation of the relationship between loneliness and medication adherence in patients with diabetes mellitus: A cross-sectional study. JIMR 46(8), 3149_ 3161. https://doi.org/10.1177/0300060518773223 (2018)

[32] T. Madeira, C. Peixoto-Plácido, N. Sousa-Santos, O. Santos, V. Alarcão, B. Goulão, C.J. Gorjão, Malnutrition among older adults living in Portuguese nursing homes: The PEN-3S study. PHN 22(3), 486-497, DOI:10.1017/S1368980018002318 (2019) 